\title{
Diatom exudates influence metabolism and cell growth of co-cultured diatom species
}

\author{
Carsten Paul, Alexandra Barofsky, Charles Vidoudez, Georg Pohnert*
}

Institute for Inorganic and Analytical Chemistry, Bioorganic Analytics, Friedrich Schiller University of Jena, Lessingstrasse 8, 07743 Jena, Germany

\begin{abstract}
We surveyed the role of chemically mediated interactions between the 2 diatom species Skeletonema costatum and Thalassiosira weissflogii. S. costatum promoted the growth of T. weissflogii in non-contact co-cultures, allowing an exchange of exuded metabolites. In contrast, cell counts of $S$. costatum were not affected by $T$. weissflogii. Metabolic profiling of the co-culture medium revealed a significant change in diatom-derived metabolites in comparison with those of monoculture controls. Several compounds detected in monocultures were not present in the co-culturing set-up, indicating either a transformation or uptake of released metabolites by the competing species. In addition, metabolic profiling of intracellular metabolites revealed that the biochemical processes of both diatoms changed in the presence of the co-cultured species. The present study illustrates that chemical cross-talk between diatom species is possible and that these types of chemical interactions lead to physiological responses and might even result in changed cell abundances.
\end{abstract}

KEY WORDS: Allelopathy $\cdot$ Metabolomics $\cdot$ Plankton interactions $\cdot$ Chemical ecology $\cdot$ Phytoplankton

\section{INTRODUCTION}

Diatoms (Bacillariophyceae) are highly abundant unicellular microalgae in ocean waters and play a crucial role in the marine food web (Fenchel 1988). In the natural environment diatoms occur in complex species assemblages and encounter stress from a variety of sources, including nutrient limitation and predation, as well as competing phytoplankton species. Stress from other phytoplankton often results from competitorinduced light or nutrient limitation (Tilman 1982). However, in some cases, phytoplankton species may also directly regulate the density of competitors via the exudation of chemical compounds. Molisch (1937) introduced the term allelopathy to apply to both inhibitory and stimulatory biochemical interactions between either primary producers or primary producers and microorganisms.

Allelopathic interactions between such phytoplankton are believed to influence plankton community composition (Maestrini \& Bonin 1981, Cembella 2003, Gross 2003, Legrand et al. 2003, Pohnert et al. 2007). The effects of toxic dinoflagellates such as Alexan- drium sp. and Karenia brevis have been particularly intensely studied. Both Alexandrium sp. (Fistarol et al. 2005) and K. brevis (Kubanek et al. 2005, Prince et al. 2008) have been reported to exude allelopathic compounds that inhibit the growth of competitors. Although in some cases allelopathic interactions between diatoms and other members of the phytoplankton community have been reported (Pratt 1966, Fistarol et al. 2004, Prince et al. 2008), little is known about the chemically mediated interactions between non-toxic diatom species (but see Sharp et al. 1979, Pouvreau et al. 2007).

In most studies of planktonic allelopathic interactions, experiments only monitor the effect of extracellular extracts or nutrient re-enriched media from a mono-culture of one species on a culture of the interacting organism. Other studies maintain mixed cultures in single culture vessels, thereby observing an overlapping effect of chemically mediated and cell contact mediated interactions (Talling 1957, Wang \& Tang 2008). Yamasaki et al. (2007) separated cultures of the diatom Skeletonema costatum and the flagellate Heterosigma akashiwo by a dialysis membrane, 
thereby physically separating the cultures but allowing chemical interaction. This type of a spatially separated co-culturing is a useful method to investigate chemical communications between phytoplankton because it allows observation of chemical cross-talk without interference from direct cell contact (e.g. McVeigh \& Brown 1954, Jensen et al. 1972, Vardi et al. 2002).

Current approaches for detecting chemically mediated interactions between plankton often consider only a small set of parameters, such as growth rate (Fistarol et al. 2005), morphology and/or the abundance of a specific class of compounds (Myklestad 1995). While useful, these approaches are often unable to detect previously unknown chemical cues and responses outside of the narrow range of established parameters. Metabolic profiling, a 'global' analysis of biological samples for low molecular mass organic metabolites, is a survey of released (exo-metabolome) and intracellular compounds (endo-metabolome). This non-targeted method allows the study of the physiological basis of signal production and reception by monitoring metabolic responses to external factors (Wilson et al. 2005).

In the present study, we combined a non-contact coculturing approach with metabolic profiling to monitor the interactions between the diatoms Skeletonema costatum and Thalassiosira weissflogii. S. costatum is an abundant diatom in ocean waters (Kooistra et al. 2008) and has been intensely studied both in terms of ecology and physiology (e.g. Granum et al. 2002, Dutz et al. 2008, Zhao et al. 2009). T. weissflogii was selected as a competitor because it is known to co-occur with $S$. costatum (e.g. in English Channel waters). The metabolic profiling included analysis of both the metabolites released into the media and the metabolites retained within the cells. We observed changes in both the metabolic profiles and in cell growth in co-cultures relative to controls, indicating a direct physiological response of one species on the presence of another. We discuss these results and how this interaction might be described in light of the concept of allelopathy.

\section{MATERIALS AND METHODS}

Cell culturing. Skeletonema costatum (Strain RCC 75) and Thalassiosira weissflogii (Strain RCC 76; can also be found in the CCMP collection strain, CCPM 1336) were obtained from the Roscoff Culture Collection (Roscoff, France). Cells were cultivated under a 14:10 h light:dark cycle at $15^{\circ} \mathrm{C}$, under illumination at approximately $80 \mu \mathrm{mol}$ photons $\mathrm{s}^{-1} \mathrm{~m}^{-2}$. The culture medium was sterilized, artificial, buffered seawater prepared as described by Maier \& Calenberg (1994).
Cells were cultivated in standing cultures of $300 \mathrm{ml}_{\text {; }}$ transfer of cultures was performed using autoclaved tools and culture vessels under a clean bench. Repeated culturing to the exponential phase and subsequent dilution was performed to guarantee similar starting conditions for both algal species despite different absolute cell counts. For larger-scale inoculations, $300 \mathrm{ml}$ of exponentially growing cultures were diluted with $1200 \mathrm{ml}$ of medium to reach cell densities of $27 \times$ $10^{3}$ and $1 \times 10^{3}$ cells $\mathrm{ml}^{-1}$ for Skeletonema costatum and Thalassiosira weissflogii, respectively. Growth rates were similar to those found in earlier studies (Montagnes \& Franklin 2001, Grossart \& Simon 2007, Vidoudez \& Pohnert 2008). Throughout the experiment samples from the outer chamber were monitored by microscopy for contamination and discarded if any increased levels of microorganisms were observed. At the end of the experiment the inner chambers were monitored for bacterial contamination, and results were not considered if contaminations were observed.

Co-culturing experiment. Dialysis tubes (dialysis tubing cellulose membrane, pore size $12 \mathrm{kDa}, 76 \mathrm{~mm} \times$ $49 \mathrm{~mm}$; Sigma Aldrich) were used to separate the cultures during co-culturing experiments. Dialysis tubes were cut into sections of approximately $32 \mathrm{~cm}$ and washed according to the recommendations of the manufacturer. After washing, one end was closed by knotting the tube. A short piece of Teflon tubing $(5 \mathrm{~cm}$ long and $3 \mathrm{~mm}$ in diameter) was attached to the other end of the dialysis tube using a nylon line. These dialysis bags were sterilized in boiling water for $15 \mathrm{~min}$ and were kept in a sterile container until use. The resulting sterile dialysis bags were inoculated with diatom cultures via the Teflon tubing. After filling, a silicon stopper was inserted into the Teflon tubing to ensure tight closure.

Co-cultures were made by transferring $100 \mathrm{ml}$ of a freshly inoculated Skeletonema costatum culture $(27 \times$ $10^{3}$ cells ml$l^{-1}$ ) to a sterilized $500 \mathrm{ml}$ glass flask with a wide mouth (Weck $\mathrm{GmbH}$ ). Using a sterile syringe, a dialysis bag was then filled with $100 \mathrm{ml}$ of a freshly inoculated Thalassiosira weissflogii culture $\left(1 \times 10^{3} \mathrm{cells} \mathrm{ml}^{-1}\right)$ and tightly closed. The dialysis bag was subsequently placed into the $S$. costatum culture, ensuring that the whole dialysis bag was submerged. The reverse co-cultures, with $S$. costatum inside the dialysis bag (referred to here as the inner culture) and $T$. weissflogii in the glass flask (referred to as the outer culture), were also prepared. This second co-culture prevented differences in growth conditions within and outside of the dialysis bag from confounding experimental results. As a control, cultures were prepared identically to the treatments except that the same species was in both the dialysis bag and in the glass flask. All treatments were performed in triplicate. A blank was prepared by filling a glass flask and the dialysis bag with $100 \mathrm{ml}$ of medium each. 
The co-cultures were agitated on a laboratory shaker at 90 rotations $\mathrm{min}^{-1}$ and cultured under the conditions described above.

Sampling and cell concentrations. All cultures were sampled under sterile conditions. To follow cell growth, samples of approximately $75 \mu \mathrm{l}$ were taken from the outer culture every 2 to $3 \mathrm{~d}$. Sampling out of the inner culture was not possible before the last day of the experiment, since dialysis bags needed to remain sealed to avoid contamination. The cell density was determined by counting at least 400 cells on a FuchsRosenthal hematocytometer with an upright microscope (Leica DM 2000, Leica).

Growth rate calculations. Growth rates $(\mu)$ were calculated as $\mu=\left(\ln N_{t}-\ln N_{0}\right) / \Delta t$, where $N_{t}$ and $N_{0}$ are cell densities at time $t$ and time 0 , respectively, and $\Delta t$ is the time difference between the measurements in days.

Extraction of extracellular and intracellular metabolites. On Day 38, the media and the cells of the outer culture and of the inner culture were independently extracted. The cells were separated from the medium by filtration on approximately $4 \mathrm{~g}$ of sand under gentle vacuum. The sand (VWR) was washed 5 times with deionized water beforehand. Sand filtration was selected since it allows separation of cells from the medium without induction of the release of metabolites due to stress, as has been observed when using other filtration techniques (Vidoudez \& Pohnert 2008). The resulting cell-free medium was extracted on solid phase extraction (SPE) cartridges (Chromabond EASY, $200 \mathrm{mg}$, Macherey-Nagel). The loaded cartridges were washed with $4 \mathrm{ml}$ of water (Chromasolv Plus, Sigma Aldrich) and eluted with a 1:1 (v:v) mixture of methanol (Chromasolv, Sigma Aldrich) and tetrahydrofurane (HiPerSolv, Chromanorm, VWR) into $4 \mathrm{ml}$ glass vials. To obtain the cell extract, the sand used for the filtration containing the cells was immediately transferred to $15 \mathrm{ml}$ tubes (Falcon) and covered with $4 \mathrm{ml}$ of methanol. After vortexing for $1 \mathrm{~min}$, the tubes were centrifuged and the methanol extract was transferred to $4 \mathrm{ml}$ glass vials. The samples were stored at $-80^{\circ} \mathrm{C}$ until analysis.

Ultra-performance liquid chromatography electrospray mass spectrometry (UPLC-ESI/MS) analysis. Metabolic profiling was performed using a Waters Acquity ultra-performance liquid chromatography (UPLC) coupled to a time of flight Q-ToF micro-mass spectrometer (Waters) equipped with electrospray ionization (ESI). Mass spectra were recorded in negative ion mode. A BEH $\mathrm{C}_{18}$ UPLC column $(2.1 \mathrm{~mm}, 1.7 \mu \mathrm{m}$; Waters) at $30^{\circ} \mathrm{C}$ was used for separation. The injection volume of each sample was $2 \mu \mathrm{l}$ and the flow rate was

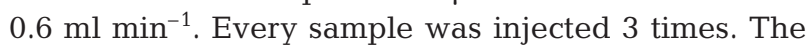
mobile phases were $0.1 \%$ formic acid and $2 \%$ acetonitrile in water (=A) and $0.1 \%$ formic acid in acetonitrile
(=B). The solvent gradient changed from $100 \% \mathrm{~A}$ to $100 \%$ B in 7 min, was held at $100 \%$ B for 2 min, was returned to $0 \% \mathrm{~B}$ by $9.5 \mathrm{~min}$ and was held at $0 \% \mathrm{~B}$ for another $30 \mathrm{~s}$ (all solvents ULC/MS, Biosolve). Mass spectra were recorded at a scan rate of $1 \mathrm{scan} \mathrm{s}^{-1}$ with an inter-scan delay of $0.1 \mathrm{~s}$ and a scan range of 100 to $1000 \mathrm{~m} / \mathrm{z}$. The collision energy was $5 \mathrm{~V}$, the sample cone was $34 \mathrm{~V}$, the cone gas flow was $150 \mathrm{l} \mathrm{N}_{2} \mathrm{~h}^{-1}$ and the desolvation gas flow was $6501 \mathrm{~N}_{2} \mathrm{~h}^{-1}$.

Statistical analysis and quantification. Unless otherwise stated, values are given as mean \pm SD. Differences in cell density were detected with a 2-tailed $t$-test assuming equal variances with Microsoft Excel 2007. For concentrations of cellular metabolites of Thalassiosira weissflogii, unequal variances were calculated and a $t$-test was performed assuming unequal variances (see Table 3). Controls and the corresponding co-cultures were compared with a 2-way repeated-measures analysis of variance (RM-ANOVA). In order to statistically analyze differences between $T$. weissflogii cultures, 1 culture was excluded due to missing data, in all other cases $n=3$. The analysis was conducted with the software Graphpad Prism 5.0. In all cases, differences were accepted as significant when $\mathrm{p}<0.05$.

Raw MS data were used to automatically generate lists of intensities of mass-retention time pairs using the normalized and mean centered peak area, calculated with Apex Track peak detection (implemented in the MarkerLynx V4.1 software supplied by Waters). These data were used for principal component analysis (PCA) employing the same software (for experimental details see Barofsky et al. 2009).

In order to compare concentration differences of certain metabolites between different treatments, the peak area was determined with the software QuanLynx V4.1 (Waters) using standard program peak detection. The area of peaks in the cell extracts were normalized to the cell density and filtered volume, medium extracts were normalized to the filtered volume. Significance of differences between peak areas were evaluated with 2 -tailed $t$-tests as described above.

\section{RESULTS}

\section{Cell densities of co-cultured diatoms}

We did not observe an effect on Skeletonema costatum cell density when it was co-cultured with Thalassiosira weissflogii (Fig. 1A). Both co-cultures and control cultures of $S$. costatum had similar growth rates $\left(0.71 \pm 0.03 \mathrm{~d}^{-1}\right.$ for the co-culture, $0.70 \pm 0.03 \mathrm{~d}^{-1}$ for the control, calculated between Days 0 and 6 ). The growth rates are not significantly different $(p=0.41)$. Logarithmic plotting of cell densities confirmed that growth 


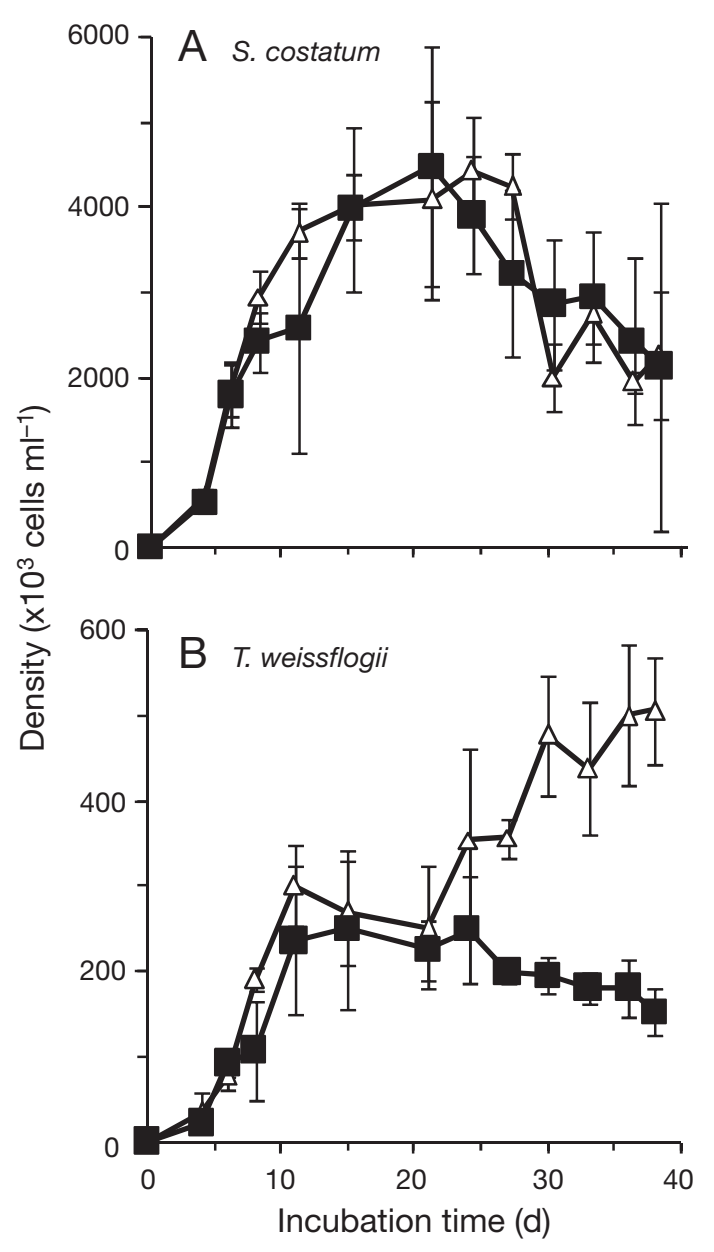

Fig. 1. Skeletonema costatum and Thalassiosira weissflogii. Growth during co-culturing. (A) Cell density of $S$. costatum in the presence of $T$. weissflogii $(\Delta)$ compared to a control in the presence of $S$. costatum ( $\mathbf{\square}$ ) and (B) cell density of $T$. weissflogii in the presence of $S$. costatum $(\Delta)$ compared to a control in the presence of $T$. weissflogii $(\square)$. Values are mean \pm SD $(\mathrm{n}=3)$, except for the co-culture $(\Delta)$ in $(\mathrm{B})$ where the values from Day 24 are given as the average and range $(n=2)$. The outer cultures of the co-culturing set-up were sampled

was exponential from Day 0 to 6 (data not shown). The maximum cell densities reached by $S$. costatum in the presence of $T$. weissflogii and in the control were nearly identical $\left(4480 \pm 1400 \times 10^{3}\right.$ cells ml $^{-1}$ [Day 21] and $4450 \pm 630 \times 10^{3}$ cells ml $^{-1}$ [Day 24], respectively). $S$. costatum reached a maximum cell concentration $3 \mathrm{~d}$ later when cultured with $T$. weissflogii than when cultured alone. However, this is not significant ( $\mathrm{p}=0.49$ ). The $S$. costatum cell concentration decreased after a period of stationary growth (Day 27). Control cell concentrations decreased after Day 21. Furthermore, a repeated-measures ANOVA showed no significant difference for the cell density between co-cultures and controls at any time point $(\mathrm{p}>0.05)$.
Significant effects on Thalassiosira weissflogii were observed during prolonged co-culturing with Skeletonema costatum. During the first $30 \mathrm{~d}$ of the experiment, the presence of $S$. costatum had no significant effect on the cell concentrations of $T$. weissflogii (Fig. 1B). T. weissflogii had a growth rate of $0.73 \pm 0.04$ and $0.76 \pm$ $0.03 \mathrm{~d}^{-1}$ for the co-culture and the control, respectively, between Days 0 and 6, which is not significantly different $(p=0.16)$. Neither co-cultures nor control cultures reached significantly different maximum cell concentrations $(\mathrm{p}=0.44)$, with $300 \pm 48 \times 10^{3}$ cells ml $^{-1}$ (Day 11) and $249 \pm 93 \times 10^{3}$ cells ml $^{-1}$ (Day 15), respectively. From Day 30 on, the cell concentrations between controls and cocultures differed. While cell concentrations of $T$. weissflogii in the control cultures decreased $\left(\mu=-0.03 \mathrm{~d}^{-1}\right.$ between Days 30 and 38), an increase in cell density ( $\mu=$ $0.01 \mathrm{~d}^{-1}$ between Days 30 and 38) in the presence of $S$. costatum was observed. That increase resulted in a final cell density of $T$. weissflogii in the co-cultures that was more than 3 times greater than the final cell density of control cultures. A repeated-measures ANOVA calculation revealed a significant difference between co-cultures and controls from Day 30 on ( $p<0.001$ for all days).

Since inner cultures were not accessible to daily sampling, we determined their cell density only on the last day of the experiments (Fig. 2). Here we observed cell concentrations of Skeletonema costatum of $1890 \pm$ $570 \times 10^{3}$ cells $\mathrm{ml}^{-1}$ for the co-cultures $(\mathrm{n}=2)$ and of $890 \pm 780 \times 10^{3}(\mathrm{n}=3)$ cells $\mathrm{ml}^{-1}$ for the control cultures (Fig. 2A). However, we were unable to test for significance because of the low number of replicates.

We found a significant difference in the cell densities of Thalassiosira weissflogii when comparing the inner cultures of the co-cultures and the control (Fig. 2B). While the cell concentration in the control was $152 \pm$ $20 \times 10^{3}$ cells $\mathrm{ml}^{-1}$, the cell concentration in the co-cultured T. weissflogii was significantly higher, with $245 \pm$ $43 \times 10^{3}$ cells ml ${ }^{-1}(\mathrm{p}<0.05)$.

We also compared the final cell concentrations of the outer and inner cultures of Skeletonema costatum and Thalassiosira weissflogii control cultures. The outer culture and inner culture of $S$. costatum had concentrations of $2150 \pm 1930 \times 10^{3}$ and $890 \pm 780 \times 10^{3}$ cells ml ${ }^{-1}$, respectively. This difference is not significant $(\mathrm{p}=$ $0.18)$. Similarly, the outer $\left(152 \pm 27 \times 10^{3}\right.$ cells ml$\left.^{-1}\right)$ and inner cultures $\left(152 \pm 20 \times 10^{3}\right.$ cells $\left.\mathrm{ml}^{-1}\right)$ of $T$. weissflogii are not significantly different $(\mathrm{p}=0.49)$.

\section{Profiling of metabolites released by diatom cells}

At the end of the experiment (Day 38), we extracted the culturing media for metabolic profiling of the extracellular metabolites based on UPLC/MS. The metabolic profiles were complex, indicating the presence of 


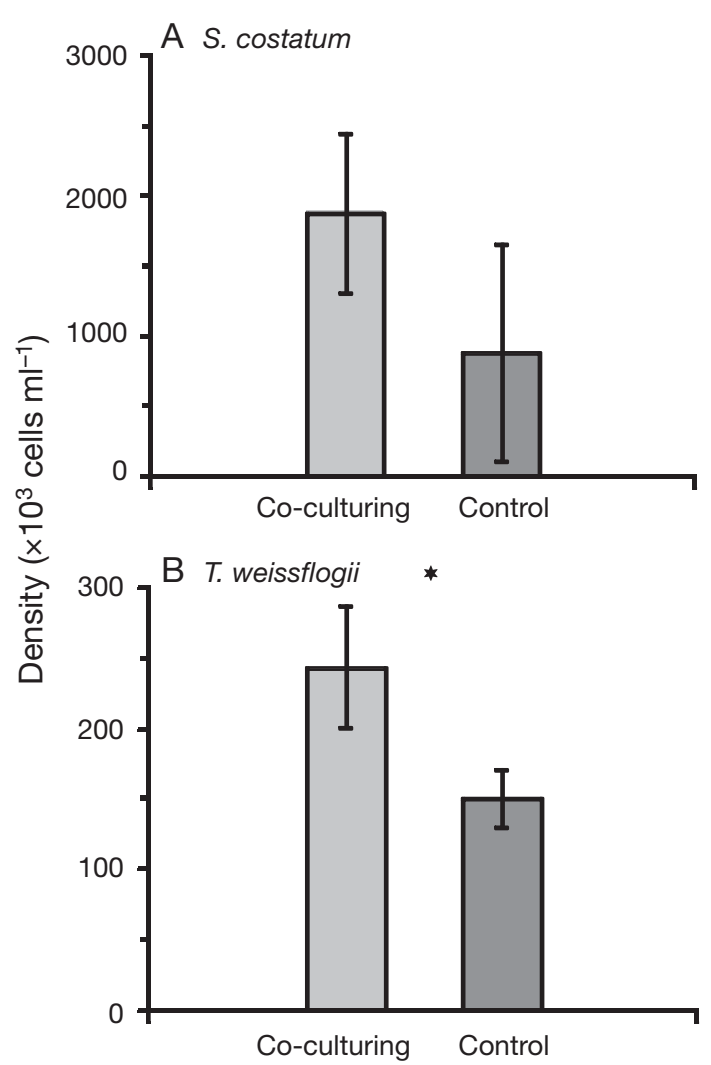

Fig. 2. Skeletonema costatum and Thalassiosira weissflogii. Cell densities on Day 38 after initiation of the co-culturing experiment. (A) Cell density of $S$. costatum in co-culture with $T$. weissflogii (light grey, $\mathrm{n}=2$ ) compared to a control in the presence of $S$. costatum (dark grey, $\mathrm{n}=3$ ) and (B) cell density of $T$. weissflogii in co-culture with $S$. costatum (light grey, $\mathrm{n}=$ 3 ) compared to a control in the presence of $T$. weissflogii (dark grey, $\mathrm{n}=3)$. ${ }^{*}$ Significant difference $(\mathrm{p}<0.05)$. Values are mean $\pm \mathrm{SD}(\mathrm{n}=3)$ or ranges $(\mathrm{n}=2)$. The inner cultures of the co-culturing set-up were counted

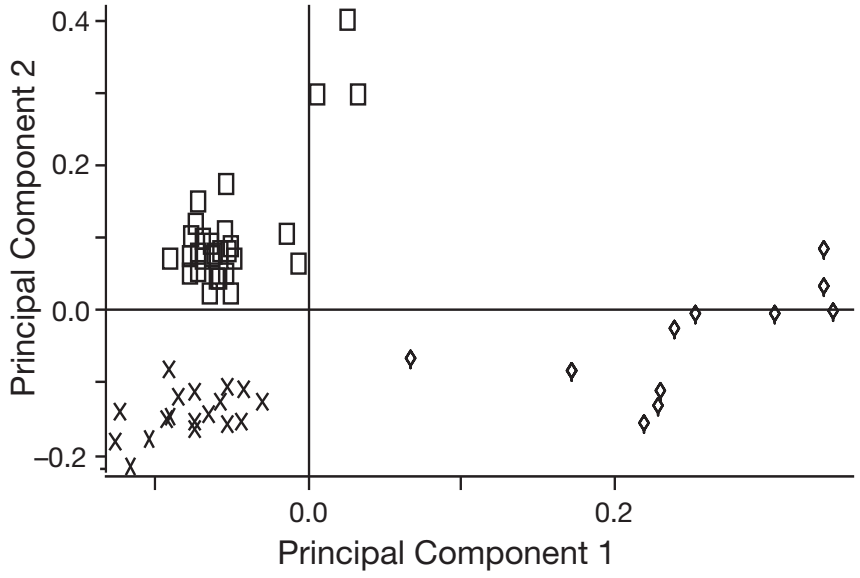

Fig. 3. Skeletonema costatum and Thalassiosira weissflogii. Resulting scores plot for principal components analysis of liquid chromatography/mass spectometry data of the released metabolites from $S$. costatum $(\diamond), T$. weissflogii $(\mathrm{X})$ and both species in a co-culturing set-up ( $\square$ ), on Day 38. Distinct clustering was observed among all 3 inoculates, demonstrating differences in the patterns of released metabolites

and T. weissflogii control extracts by Principal Component 2 . The $\mathrm{m} / \mathrm{z}$-retention time pairs responsible for the group separation of the phases were extracted using the corresponding loadings plot, and only those not found in the blank measurements were further considered. Table 1 shows a selection of 8 substances that were exclusively found in the medium extract of $S$. costatum. Similarly, we found 1 substance with a masscharge ratio of 241 ( $2 \mathrm{~min}$ ) that was only detected in the medium extract of $T$. weissflogii control cultures, but not in the medium extract of the $S$. costatum control cultures or in the co-cultures (Table 1). numerous released metabolites in the medium. We therefore relied on automatic peak processing to form massretention time pairs that could be evaluated for differences in intensities of released metabolites. PCA was used to compare the intensity of all these pairs between all chromatograms. The differences between extracellular profiles were visualized using a scores plot of medium extracts. The resulting scores plot shows a separation into 3 groups (Fig. 3). The medium extracts of Skeletonema costatum and Thalassiosira weissflogii were separated by Principal Component 1, while the medium extracts of the co-cultures were separated from the $S$. costatum
Table 1. Relative concentrations (given as a function of the intensity of the respective signals in single ion chromatograms normalized to the extracted volume) of 9 selected extracellular substances in the co-culture $(\mathrm{n}=5)$, Skeletonema costatum control $(\mathrm{n}=2)$ and Thalassiosira weissflogii control $(\mathrm{n}=3)$. Values are mean $\pm \mathrm{SD}(\mathrm{n}=3)$ or ranges $(\mathrm{n}=2) . \mathrm{m} / \mathrm{z}$ : mass to charge ratios of the respective compounds, the time refers to the retention time in the ultraperformance liquid chromatography; ND: not detectable, signal-to-noise ratio $(\mathrm{S} / \mathrm{N})<3$; traces: $\mathrm{S} / \mathrm{N}<10$; quantified: $\mathrm{S} / \mathrm{N}>10$

\begin{tabular}{|lccc|}
\hline Parameter & Co-culture & S. costatum & T. weissflogii \\
\hline$m / z 121$ at $1.45 \mathrm{~min}$ & Traces & $38.1 \pm 2.1$ & Traces \\
$\mathrm{m} / z 239$ at $2.86 \mathrm{~min}$ & $\mathrm{ND}$ & $30.2 \pm 7.3$ & $\mathrm{ND}$ \\
$\mathrm{m} / z 241$ at $1.99 \mathrm{~min}$ & $\mathrm{ND} /$ traces & $\mathrm{ND}$ & $2.2 \pm 0.2$ \\
$\mathrm{~m} / z 241$ at $4.93 \mathrm{~min}$ & $\mathrm{ND}$ & $9.3 \pm 4.0$ & $\mathrm{ND}$ \\
$\mathrm{m} / z 269$ at $5.73 \mathrm{~min}$ & $\mathrm{ND}$ & $6.6 \pm 1.6$ & $\mathrm{ND}$ \\
$\mathrm{m} / z 277$ at $3.85 \mathrm{~min}$ & $\mathrm{ND}$ & $7.1 \pm 4.7$ & $\mathrm{ND}$ \\
$\mathrm{m} / z 301$ at $2.39 \mathrm{~min}$ & $\mathrm{ND}$ & $11.0 \pm 2.2$ & $\mathrm{ND}$ \\
$\mathrm{m} / z 309$ at $4.49 \mathrm{~min}$ & $\mathrm{ND}$ & $12.8 \pm 4.3$ & $\mathrm{ND}$ \\
$\mathrm{m} / z 351$ at $3.00 \mathrm{~min}$ & $\mathrm{ND}$ & $42.7 \pm 13.8$ & $\mathrm{ND}$ \\
\hline
\end{tabular}




\section{Profiling of cellular metabolites}

We used the same methods for the analysis of the metabolic profile of intracellular compounds. Again, the number of detected metabolites led us to use automatic data extraction and PCA to detect the metabolites that are produced in different amounts in cells of co-culturing and control set-ups. The resulting scores plot shows separation between the Skeletonema costatum cells in co-cultures and $S$. costatum cells in controls (not shown). This analysis revealed differences between metabolites present in control $S$. costatum cells and co-cultured $S$. costatum cells. Both up- and down-regulation of metabolites in response to co-culturing was observed, and a selection of metabolites is given in Table 2. One example is the significantly higher normalized peak area of a substance with $481 \mathrm{~m} / \mathrm{z}$ at $4.4 \mathrm{~min}$ in co-cultured $S$. costatum cells compared to the control cells ( $\mathrm{p}<0.001$ ) (Table 2$)$. In Thalassiosira weissflogii cells we were also able to detect significantly different concentrations $(p<0.05)$ of several substances (e.g. $\mathrm{m} / \mathrm{z} 527$ at $4.2 \mathrm{~min}$ ) between the cell extracts of the co-cultures and the control cultures (Table 3). Here the concentration of all listed compounds was lower in the co-cultures than in the controls.

\section{DISCUSSION}

In the present study, we addressed the role of chemical exudates and potential chemical signals on diatom cultures grown under a regime that prevented cell contact but allowed cultures to exchange chemicals. This type of co-culturing experiment is often used in plankton ecology to evaluate the effects of diffusible signals and nutrients (McVeigh \& Brown 1954, Jensen et al. 1972, Vardi et al. 2002, Yamasaki et al. 2007). Using this experimental design allowed us to exclude potential effects of cell contact (previously described by Uchida et al. 1995) and to observe only interactions mediated by metabolites and nutrients diffusing through the dialysis membrane. Because the experiment was conducted with larger volumes of culture medium than described by Yamasaki et al. (2007), we were able to sample enough medium to create a comprehensive profile of the metabolites released by diatoms and of the metabolic changes within the cells upon co-culture using LC/MS techniques. In contrast to numerous previous experiments, where culture filtrates from monocultures or partially purified compounds were used to test for allelopathy (e.g. Suikkanen et al. 2005), our method allowed us not only to monitor the action of exuded stable compounds but also to cover unstable compounds. In addition, interactions such as the induced production of allelopathic compounds in the presence of the competitor (e.g. Selander et al. 2006) or indirectly mediated chemical interactions via nutrient effects or secondary interactions involving microorganisms as an additional partner, can be observed. Control experiments, in which the same alga was grown within and outside the dialysis bag, show that there are no significant differences in cell counts between compartments. This suggests that growth conditions are independent of the cul-

One of the 6 replicates was id
deleted from the calculations 
ture compartment, and the effects of shading or poor aeration (Pouvreau et al. 2007) that could potentially influence the outcome of the co-culturing can be excluded. Although our culture conditions do not represent the natural planktonic environment due to increased cell counts and artificially enriched nutrient conditions, we can conclude that there is a general possibility of an allelopathic response of diatoms to the presence of co-occurring species (Legrand et al. 2003).

Co-culturing Skeletonema costatum and Thalassiosira weissflogii had no effect on the growth of $S$. costatum. When cultured in the outer chamber $S$. costatum exhibited similar growth rates independent of the presence of $T$. weissflogii or S. costatum in the inner chamber (Fig. 1A). An exponential growth phase, with growth rates comparable to those detected in previous studies using these species (Montagnes \& Franklin 2001, Vidoudez \& Pohnert 2008), was followed by a short stationary phase and a declining phase in the co-cultures as well as in the control (Fig. 1A). This illustrates that low molecular weight exudates of $T$. weissflogii diffusing through the dialysis membrane do not influence the growth of $S$. costatum. In addition, competition for nutrients, which also diffuse through the membrane, does not influence the performance of $S$. costatum. These results were verified by evaluating cell concentrations in the inner chamber after the end of other co-culturing experiments. No differences in cell concentration of $S$. costatum were observed in controls or in the presence of $T$. weissflogii (Fig. 2A). Such a lack of allelopathic interactions was also found in other co-culturing experiments (e.g. Talling 1957) and under natural conditions, where, e.g. Heterosigma akashiwo dynamics during a spring bloom were under nutrient but not allelopathic control (Shikata et al. 2008). In contrast, T. weissflogii was affected by compounds exuded from the $S$. costatum culture chamber. Initially, both control cultures and co-cultures of $T$. weissflogii had similar growth rates. However, after a period of stationary growth, the cell density of the co-cultured $T$. weissflogii significantly increased. These cultures eventually reached a cell concentration more than 3 times greater than that in the controls (Fig. 1B). Again, these observations were confirmed because cell concentrations of $T$. weissflogii were significantly higher in the chambers of the co-cultures than in those of the controls (Fig. 2B). Possible explanations for the stimulated growth of $T$. weissflogii include a positive allelopathic effect of one or more compounds that were released by $S$. costatum cultures only during the declining phase. Similar biphasic growth curves can also be observed in cultures of bacteria where switches of cell physiology dependent on quorum sensing might result in increased performance in the medium (van Houdt et al. 2007). That a comparable process depending on signaling in-between individual cells of $T$. weissflogii is responsible for the observed biphasic growth (Fig. 1B) is unlikely, since control experiments with this species alone and previous culturing did not indicate any sign of positive feedback within cultures of this alga. Although care was taken to avoid microbial contamination and cultures were discarded if contaminated, it cannot be fully excluded that other mediating organisms such as an associated bacteria may also be involved in the observed chemical interaction.

Most of the studies concerning allelopathic interactions have focused on negative allelopathic effects (e.g. Gross 2003, Kubanek et al. 2005). Yamasaki et al. (2007) found, for example, that the first species to dominate in a co-culturing experiment with Skeletonema costatum and Heterosigma akashiwo was generally able to reduce the growth of the other co-cultured species. In contrast, there are only a few examples of positive allelopathic interactions. Recent studies have reported that cyanobacterial filtrates stimulate the growth of a wide range of organisms in a natural phytoplankton community, such as chlorophytes, dinoflagellates and other cyanobacteria (Suikkanen et al. 2005). Bacteria are also known to promote algal growth (Grossart \& Simon 2007). Additionally, low concentrations of Prymnesium parvulum toxins have a positive effect on the growth rate of other algae (Graneli \& Pavia 2006). A stimulatory effect was also observed for $S$. costatum in interactions with the macroalga Ulva pertusa (Nan et al. 2004). Nan et al. (2004) observed a growth stimulation of $U$. pertusa when grown in the presence of this diatom. It would be interesting to investigate in future experiments whether Skeletonema spp. generally promote the growth of other marine micro- and macroalgae and if this effect is limited to the late growth phases of these algae.

Another possible explanation for the increase of Thalassiosira weissflogii cell counts is that Skeletonema costatum in the declining phase might liberate nutrients that are exploited for a delayed second increase in cell density (Fig. 1B). Discriminating between allelopathic and nutrient effects is a general problem in allelopathy research (Rengefors \& Legrand 2001), and a final answer can only be found through bioassayguided structure elucidation of the active components. Furthermore, the possibility of the involvement of bacteria that could influence diatom cell counts cannot be fully excluded, even though the utmost care was taken to exclude bacteria and constant monitoring confirmed a low level of contamination in all cultures.

We reasoned that a metabolic profiling approach to monitor the differences in cellular metabolites, as well as those in the medium, might provide insight into the 
nature of chemically mediated interactions between diatom species. Metabolic profiling is a well-established method in plant biology for monitoring induced changes in the metabolism of plants due to biotic interactions (von Roepenack-Lahaye et al. 2004). In contrast, only a few attempts have been made to profile the endo- (Allen et al. 2008) or exo-metabolome of diatoms (Barofsky et al. 2009). Direct comparisons of metabolites released by Skeletonema costatum and Thalassiosira weissflogii using MS techniques and data evaluation based on multivariate statistical analysis support the idea of a species-specific extracellular metabolic profile of both diatoms (Fig. 3, Table 1). The method introduced here allows a rapid separation of metabolites on a reversed-phase column; coupling to a mass spectrometer then gives a profile of numerous eluted metabolites that can be classified based on their retention times and characteristic mass to charge ratios. Using this approach $>100$ metabolites can be detected at a given time in the culture medium. Thus, multivariate statistical methods had to be used to unravel the quantitative variations of exuded metabolites (Barofsky et al. 2009). We found substances that were exclusively present either in $S$. costatum or in $T$. weissflogii control cultures. Interestingly, none of these species-specific substances were present in the co-culture, indicating an obvious interaction involving released metabolites (Table 1). Inhibition of either biosynthesis or of excretion of these compounds by the competitor might cause the observed change in metabolic profiles. Alternatively, an active uptake or transformation of these particular compounds by the co-cultured diatoms might cause the observed effect. Heterotrophic utilization of organic compounds by diatoms has been discussed as an important survival strategy of diatoms under adverse conditions (Tuchman et al. 2006). Such heterotrophic uptake might indeed be responsible for the promoted T. weissflogii growth in our co-culturing experiments. An active uptake of specific phytoplankton-derived metabolites such as dimethylsulfoniopropionate (DMSP) by other phytoplankton species has recently been shown (VilaCosta et al. 2006). Our methods, based on LC/MS measurements, do not provide any structural information beside the retention times in reversed-phase chromatography and the mass to charge ratios of the [M$\mathrm{H}]^{-}$ions. Available databases established for electrospray mass spectrometry metabolomics of higher plants could not be successfully applied to diatom metabolites. Nevertheless, this basic mass spectrometric information allows us to exclude the possibility that the observed metabolites are amino acids or extracellular carbohydrates, which make up the bulk of compounds released from $S$. costatum (Granum et al. 2002). We also found that DMSP or other betains were not among the metabolites that were present in significantly different concentrations between control cultures and co-cultures. We suggest that further structural elucidation of the observed metabolites and direct tests of their biological activity might provide a shortcut for the identification of an active principle when compared to traditional bioassay-guided structure elucidation (Pohnert et al. 2007)

Although cell density of Skeletonema costatum was not affected by the co-cultured Thalassiosira weissflogii, we still observed a physiological response to the presence of the competitor. This is indicated by a change in the intracellular metabolic profile observed after PCA of data derived from cellular extracts (prominent changes illustrated in Table 2). The change in intracellular metabolic profile indicates that $S$. costatum is capable of perceiving the presence of a competitor by chemical signals that diffuse through the dialysis membrane or of reacting to the altered nutrient availability caused by the co-cultivation. Other compounds, such as those shown in Table 3, from the intracellular extracts of $T$. weissflogii are downregulated in the co-culture. Physiological responses to changing conditions that are reflected in a change of the metabolic profile are well documented in the literature (Ribalet et al. 2007, Van Mooy et al. 2009). The extent to which these changes have a direct impact on ecological interactions is by no means clear, but observation of metabolic fluctuations will enable a targeted screening of biochemical and ecological responses to specific metabolites, as has been successfully demonstrated in the case of dimethyl sulfide and polyunsaturated aldehydes (Pohnert 2005, Steinke et al. 2006).

Despite being conducted in the laboratory under conditions far from those in field situations, our experiments provide evidence that diatoms have the potential to interact with each other via released metabolites. These interactions may result in a complex cross-talk between diatom species that might even be overlaid by contributions from the bacterial community (Grossart \& Simon 2007). Our experiments are consistent with other studies showing that exudates of one phytoplankton species can influence the growth of another one (Fistarol et al. 2004, Kubanek et al. 2005, Yamasaki et al. 2007, Wang \& Tang 2008). We link altered growth to a modified chemical profile of both the released and intracellular metabolites, thereby showing that diffusible compounds are involved in an interaction not only reflected by changes in cell concentrations but also by changes in the physiology of the cells. This is very much in line with previous observations of induced responses of phytoplankton species to external stimuli (e.g. Selander et al. 2006). Our results show the importance of tests for allelopathy, which allow for direct interactions, as compared with 
established approaches, which primarily test the activity of the culture medium of isolated species. It is interesting to note that we observed these types of chemically mediated interactions between diatoms that co-occur in the same habitat.

Acknowledgements. We thank the Volkswagen Stiftung and the Jena School for Microbial Communication for funding. Dr. E. K. Prince is acknowledged for her improvements of the manuscript.

\section{LITERATURE CITED}

Allen AE, LaRoche J, Maheswari U, Lommer M and others (2008) Whole-cell response of the pennate diatom Phaeodactylum tricornutum to iron starvation. Proc Natl Acad Sci USA 105:10438-10443

Barofsky A, Vidoudez C, Pohnert G (2009) Metabolic profiling reveals growth stage variability in diatom exudates. Limnol Oceanogr Methods 7:382-390

Cembella AD (2003) Chemical ecology of eukaryotic microalgae in marine ecosystems. Phycologia 42:420-447

Dutz J, Koski M, Jonasdottir SH (2008) Copepod reproduction is unaffected by diatom aldehydes or lipid composition. Limnol Oceanogr 53:225-235

Fenchel T (1988) Marine plankton food chains. Annu Rev Ecol Syst 19:19-38

Fistarol GO, Legrand C, Selander E, Hummert C, Stolte W, Granéli E (2004) Allelopathy in Alexandrium spp.: effect on a natural plankton community and on algal monocultures. Aquat Microb Ecol 35:45-56

Fistarol GO, Legrand C, Granéli E (2005) Allelopathic effect on a nutrient-limited phytoplankton species. Aquat Microb Ecol 41:153-161

Granéli E, Pavia H (2006) Allelopathy in marine ecosystems. In: Reigosa MJ, Pedrol N, González L (eds) Allelopathya physiological process with ecological implications. Springer, Dordrecht

Granum E, Kirkvold S, Myklestad SM (2002) Cellular and extracellular production of carbohydrates and amino acids by the marine diatom Skeletonema costatum: diel variations and effects of N depletion. Mar Ecol Prog Ser 242: 83-94

Gross EM (2003) Allelopathy of aquatic autotrophs. Crit Rev Plant Sci 22:313-339

Grossart HP, Simon M (2007) Interactions of planktonic algae and bacteria: effects on algal growth and organic matter dynamics. Aquat Microb Ecol 47:163-176

Jensen A, Rystad B, Skoglund L (1972) The use of dialysis culture in phytoplankton studies. J Exp Mar Biol Ecol 8: 241-248

Kooistra WHCF, Sarno D, Balzano S, Gu H, Andersen RA, Zingone A (2008) Global diversity and biogeography of Skeletonema species (Bacillariophyta). Protist 159: 177-193

Kubanek J, Hicks MK, Naar J, Villareal TA (2005) Does the red tide dinoflagellate Karenia brevis use allelopathy to outcompete other phytoplankton? Limnol Oceanogr 50: 883-895

Legrand C, Rengefors K, Fistarol GO, Granéli E (2003) Allelopathy in phytoplankton - biochemical, ecological and evolutionary aspects. Phycologia 42:406-419

Maestrini SY, Bonin DJ (1981) Allelopathic relationships between phytoplankton species. Can Bull Fish Aquat Sci
210:323-338

Maier I, Calenberg M (1994) Effect of extracellular $\mathrm{Ca}^{2+}$ and $\mathrm{Ca}^{2+}$-antagonists on the movement and chemoorientation of male gametes of Ectocarpus siliculosus (Phaeophyceae). Bot Acta 107:451-460

McVeigh I, Brown WH (1954) In vitro growth of bold and Haematococcus pluvialis Flotow em. Wille in mixed cultures. Bull Torrey Bot Club 81:218-223

Molisch H (1937) Der Einfluss einer Pflanze auf die andereAllelopathie. Fischer Verlag, Jena

Montagnes DJS, Franklin DJ (2001) Effect of temperature on diatom volume, growth rate, and carbon and nitrogen content: reconsidering some paradigms. Limnol Oceanogr 46: 2008-2018

Myklestad SM (1995) Release of extracellular products by phytoplankton with special emphasis on polysaccharides. Sci Total Environ 165:155-164

Nan C, Zhang H, Zhao G (2004) Allelopathic interactions between the macroalga Ulva pertusa and eight microalgal species. J Sea Res 52:259-268

Pohnert G (2005) Diatom/copepod interactions in plankton: the indirect chemical defense of unicellular algae. ChemBioChem 6:946-959

Pohnert G, Steinke M, Tollrian R (2007) Chemical cues, defence metabolites and the shaping of pelagic interspecific interactions. Trends Ecol Evol 22:198-204

Pouvreau JB, Housson E, Tallec LL, Morançais M, Rincé Y, Fleurence J, Pondaven P (2007) Growth inhibition of several marine diatom species induced by the shading effect and allelopathic activity of marennine, a blue-green polyphenolic pigment of the diatom Haslea ostrearia (Gaillon/Bory) Simonsen. J Exp Mar Biol Ecol 352: 212-225

Pratt DM (1966) Competition between Skeletonema costatum and Olisthodiscus luteus in Narragansett Bay and in culture. Limnol Oceanogr 11:447-455

Prince EK, Myers TL, Kubanek J (2008) Effects of harmful algal blooms on competitors: allelopathic mechanisms of the red tide dinoflagellate Karenia brevis. Limnol Oceanogr 53:531-541

Rengefors K, Legrand C (2001) Toxicity in Peridinium aciculiferum-an adaptive strategy to outcompete other winter phytoplankton? Limnol Oceanogr 46:1990-1997

Ribalet F, Wichard T, Pohnert G, Ianora A, Miralto A, Casotti R (2007) Age and nutrient limitation enhance polyunsaturated aldehyde production in marine diatoms. Phytochemistry 68:2059-2067

Selander E, Thor P, Toth G, Pavia H (2006) Copepods induce paralytic shellfish toxin production in marine dinoflagellates. Proc R Soc Lond B 273:1673-1680

Sharp JH, Underhill PA, Hughes DJ (1979) Interaction (allelopathy) between marine diatoms: Thalassiosira pseudonana and Phaeodactylum tricornutum. J Phycol 15: 353-362

Shikata T, Yoshikawa S, Matsubara T, Tanoue W and others (2008) Growth dynamics of Heterosigma akashiwo (Raphidophyceae) in Hakata Bay, Japan. Eur J Phycol 43: 395-411

Steinke M, Stefels J, Stamhuis E (2006) Dimethyl sulfide triggers search behavior in copepods. Limnol Oceanogr 51: 1925-1930

Suikkanen S, Fistarol GO, Granéli E (2005) Effects of cyanobacterial allelochemicals on a natural plankton community. Mar Ecol Prog Ser 287:1-9

Talling JF (1957) The growth of two plankton diatoms in mixed cultures. Physiol Plant 10:215-223

Tilman D (1982) Resource competition and community struc- 
ture. Princeton University Press, Princeton, NJ

Tuchman NC, Schollett MA, Rier ST, Geddes P (2006) Differential heterotrophic utilization of organic compounds by diatoms and bacteria under light and dark conditions. Hydrobiologia 561:167-177

Uchida T, Yamaguchi M, Matsuyama Y, Honjo T (1995) The red-tide dinoflagellate Heterocapsa sp. kills Gyrodinium instriatum by cell contact. Mar Ecol Prog Ser 118:301-303

> van Houdt R, Aertsen A, Michiels CW (2007) Quorumsensing-dependent switch to butanediol fermentation prevents lethal medium acidification in Aeromonas hydrophila AH-1N. Res Microbiol 158:379-385

> Van Mooy BAS, Fredricks HF, Pedler BE, Dyhrman ST and others (2009) Phytoplankton in the ocean use non-phosphorus lipids in response to phosphorus scarcity. Nature 458:69-72

Vardi A, Schatz D, Beeri K, Motro U, Sukenik A, Levine A, Kaplan A (2002) Dinoflagellate-cyanobacterium communication may determine the composition of phytoplankton assemblage in a mesotrophic lake. Curr Biol 12:1767-1772

Vidoudez C, Pohnert G (2008) Growth phase-specific release of polyunsaturated aldehydes by the diatom Skeletonema marinoi. J Plankton Res 30:1305-1313

Editorial responsibility: Graham Savidge,

Portaferry, UK
Vila-Costa M, Simo R, Harada H, Gasol JM, Slezak D, Kiene RP (2006) Dimethylsulfoniopropionate uptake by marine phytoplankton. Science 314:652-654

von Roepenack-Lahaye E, Degenkolb T, Zerjeski M, Franz M and others (2004) Profiling of arabidopsis secondary metabolites by capillary liquid chromatography coupled to electrospray ionization quadrupole time-of-flight mass spectrometry. Plant Physiol 134:548-559

> Wang Y, Tang X (2008) Interactions between Prorocentrum donghaiense Lu and Scrippsiella trochoidea (Stein) Loeblich III under laboratory culture. Harmful Algae 7:65-75

Wilson ID, Plumb R, Granger J, Major H, Williams R, Lenz EM (2005) HPLC-MS-based methods for the study of metabonomics. J Chromatogr B 817:67-76

Yamasaki Y, Nagasoe S, Matsubara T, Shikata T, Shimasaki Y, Oshima Y, Honjo T (2007) Allelopathic interactions between the bacillariophyte Skeletonema costatum and the raphidophyte Heterosigma akashiwo. Mar Ecol Prog Ser 339:83-92

Zhao Y, Yu Z, Song X, Cao X (2009) Biochemical compositions of two dominant bloom-forming species isolated from the Yangtze River Estuary in response to different nutrient conditions. J Exp Mar Biol Ecol 368:30-36

Submitted: March 12, 2009; Accepted: June 14, 2009 Proofs received from author(s): September 1, 2009 